\title{
APRESENTAÇÃO: O GT TRABALHO E EDUCAÇÃO DA ANPED1
}

Célia Regina Vendramini² Mariléia Maria da Silva ${ }^{3}$

Os trabalhos reunidos no número 29 da Revista Trabalho Necessário contam com artigos de demanda contínua e artigos que integram um número temático acerca de temas e questões que compõem os desafios dos estudos acerca da relação trabalho e educação. Há algumas décadas, as pesquisas no Brasil vêm acompanhando e analisando as transformações no mundo do trabalho e suas repercussões na educação e na escola. Tais pesquisas têm como pressuposto 0 trabalho como base sobre a qual se desenvolvem os diferentes e complexos elementos que constituem o ser humano, sua história, sociabilidade, cultura e, portanto, sua educação.

As pesquisas sobre as relações entre o mundo do trabalho e a educação dão suporte e também são estimuladas pelo GT Trabalho e Educação. Um dos Grupos de Trabalho (GT09) da Associação Nacional de Pós-Graduação e Pesquisa em Educação - ANPED. Trata-se de um fórum de discussão que congrega pesquisadores do país visando a articulação dos mesmos, a socialização do conhecimento, o aprofundamento teórico-metodológico, o debate sobre questões relacionadas ao trabalho e à educação e o estímulo para o estudo de temas emergentes. Os pesquisadores do GT encontram-se nas reuniões regionais e nacionais da Associação, bem como em outros fóruns, como o Intercrítica - Intercâmbio Nacional dos Núcleos de Pesquisa em Trabalho e Educação. Os artigos que compõem este número temático foram apresentados e debatidos na 38 ${ }^{\underline{a}}$ Reunião Nacional da Anped, realizada em outubro de 2017 na Universidade Federal do Maranhão, em São Luís.

O tema da Reunião Nacional versou sobre a Democracia em risco: a pesquisa e a pós-graduação em contexto de resistência. Ela se realizou no contexto pós golpe parlamentar de 2016 contra a presidente Dilma Rousseff, do Partido dos Trabalhadores - PT, e foi seguido por uma sucessão de medidas

\footnotetext{
${ }^{1}$ DOI: https://doi.org/10.22409/tn.16i29.p4551

${ }^{2}$ Doutora em Educação. Professora na Universidade Federal de Santa Catarina - UFSC.

E-mail: celia.vendramini@ufsc.br

${ }^{3}$ Doutora em Educação. Professora na Universidade Estadual de Santa Catarina - UDESC.

E-mail: marileiamaria@hotmail.com
}

TrabalhoNecessário- www.uff.br/revistatrabalhonecessario: ano 16, №29/2018 
ultrarreacionárias. O PT governou o país por 14 anos dentro do modelo da conciliação de classes e da teoria neodesenvolvimentista, não resultando na alteração do quadro de extrema desigualdade social do país. De acordo com Safatle ${ }^{3}$, "o lulismo não representou uma política de combate à desigualdade, mas uma política de capitalização dos pobres". Entretanto, o que se seguiu foi um capitalismo ainda mais expropriador determinando um conjunto de contrarreformas trabalhista, previdenciária e educacional. Particularmente no campo da educação, podemos citar a contrarreforma do ensino médio, a qual rebaixa e fragmenta ainda mais a formação dos jovens, e o Projeto Escola Sem Partido, ou a "escola com mordaça", o qual visa retirar da escola o conteúdo relacionado com a vida, o trabalho, as classes sociais, as religiões de diferentes matizes, as questões de gênero, entre outras, constituindo-se em afronta ao pensamento crítico $^{4}$. Nesse contexto, o tema da democracia ganhou relevo, bem como a necessidade da resistência no campo político e acadêmico.

Os temas que circularam no GT Trabalho e Educação foram além do debate sobre a democracia burguesa e adentraram questões mais amplas e profundas, em correspondência com o contexto em que vivemos e a trajetória do GT. Nos 100 anos da Revolução Russa, refletimos sobre a educação socialista em termos de concepção e experiências históricas revolucionárias do século XX; no ano em que as mulheres realizaram um dia memorável de greve internacional (8 de março), debatemos as questões de gênero, trabalho, classe e patriarcado.

O trabalho encomendado à professora Helena Hirata - do Centre National de la Recherche Scientifique (CNRS), França - uma colaboradora de longa data do GT, versou sobre a relação entre Gênero, patriarcado, trabalho e classe, provocando uma profícua discussão entre os participantes da $38^{\mathrm{a}}$ Reunião Nacional da Anped. Algumas das questões que se apresentaram no debate foram: a classe é uma categoria fundante que se expressa nas diferenças de gênero, raça, geração? Há ou não uma hierarquização destas categorias? A resposta a estas questões não é simples, e em seu texto Hirata expõe de maneira pormenorizada a complexidade que tal temática vem ganhando ao longo do

\footnotetext{
${ }^{3}$ Vladimir Safatle, Só mais um esforço, Editora Três Estrelas, 2017.

${ }^{4}$ Ver o livro organizado por Gaudêncio Frigotto: Escola "sem" partido: esfinge que ameaça a educação e a sociedade brasileira. Publicado pelo Laboratório de Políticas Públicas da Universidade do Estado do Rio de Janeiro (UERJ). Disponível em:http://bit.ly/2vzqPn6.
}

TrabalhoNecessário- www.uff.br/revistatrabalhonecessario: ano 16, №29/2018 
tempo. Apresenta, e ao mesmo tempo problematiza, conceitos e categorias desenvolvidos por pesquisadores e pesquisadoras no Brasil, na França e em outros países, sublinhando seus pontos de divergências e de complementaridades. Dividido em três partes, a autora inicia o seu artigo definindo brevemente o que seria o materialismo feminista, abarcando em seguida a temática do trabalho entre as mulheres, bem como a relação entre trabalho e gênero no contexto do que entende como o de "um capitalismo patriarcal". Posteriormente, apresenta a discussão em torno do paradigma da interseccionalidade no qual está proposto a interdependência e a nãohierarquização das relações de poder de gênero, raça e classe social. Sem dúvida, são proposições extremamente instigantes, que nos impelem ao debate.

O minicurso sobre a Pedagogia Socialista, ministrado no fórum do GT Trabalho e Educação, foi desenvolvido pelas professoras Maria Ciavatta da Universidade Federal Fluminense e Carmen Sylvia Vidigal Mores da Universidade de São Paulo, as quais analisaram a questão conceitual da educação socialista, bem como algumas concepções e iniciativas educacionais de objetivos emancipatórios, considerando experiências históricas revolucionárias e outras vinculadas a movimentos sociais e políticos. Como resultado do minicurso, contamos com dois artigos para este número temático.

O artigo da Maria Ciavatta sobre os Caminhos da educação socialista procura evidenciar que a educação socialista não é uma abstração, sua concepção tem raízes históricas no conjunto das relações que a determinam no tempo e no espaço dos processos revolucionários. A autora vai buscar em Marx e Gramsci os princípios básicos da pedagogia socialista ou da ideia de "seres humanos plenamente desenvolvidos". A apresentação e reflexão sobre os caminhos da educação socialista parte de uma contextualização dos grandes processos revolucionários onde se gerou a ideia da emancipação humana e da pedagogia socialista. Em seguida, são abordadas algumas experiências realizadas na Revolução Russa, na Revolução Cubana e na perspectiva da pedagogia socialista do Movimento dos Trabalhadores Rurais sem Terra (MST) no Brasil. Segundo Ciavatta, a "pedagogia socialista, além de ser um ideário nascido das ideias de emancipação, das revoltas e de grandes revoluções, é uma concepção de ser humano e de educação". 
Na esteira da reflexão sobre a educação de caráter emancipatório, temos o artigo de Carmen Sylvia Vidigal Moraes e Doris Accioly e Silva intitulado Circuitos educativos: a Escola Moderna N. 1 e os Ginásios Vocacionais Noturnos, um estudo comparativo. O foco volta-se para a sociedade brasileira, buscando evidenciar propostas educacionais que se contrapunham aos modelos hegemônicos de escolarização, particularmente de iniciativa do movimento operário e sindical (no caso, os anarco-sindicalistas). O percurso do ideário anarquista apresenta-se na organização da Escola Moderna n. 1 (1912 a 1919) e no projeto pedagógico dos Ginásios Vocacionais Noturnos (anos 1960) destinados a jovens e adultos trabalhadores.

As autoras trabalham com fontes primárias e secundárias do Centro de Memória de Educação, da Faculdade de Educação da USP e do Centro de Documentação e Informação Científica "Professor Casimiro dos Reis Filho" Cedic, da PUC de São Paulo. O artigo resgata práticas educacionais operárias, sejam as escolares ou a imprensa anarquista e operária, a qual assume, segundo as autoras, "forte dimensão educadora do operariado por meio da divulgação tanto dos ideais anarquistas quanto das teorias da educação racionalista, promovendo um campo de disputas em torno do modelo escolar operário".

O debate fomentado pelos dois artigos acima sobre a pedagogia socialista revela a existência de importantes iniciativas emancipatórias de educação e a disputa em torno de projetos pedagógicos diferenciados. Eles são inspiradores para nossa ação política e prática pedagógica no enfrentamento necessário diante de uma educação e escola hegemonicamente marcada pela dualidade estrutural, pela formação unilateral sem conexão com a vida e o trabalho.

Quanto aos trabalhos apresentados no GT Trabalho e Educação, dos quais alguns compõem este número temático, eles versam sobre a formação em diferentes contextos na relação com o trabalho. Com base em uma concepção de formação integral, analisam a práxis e formação política de trabalhadores, as contradições da educação em cursos de formação de profissionais da saúde, na formação de soldados, nos Institutos Federais de Educação e seu desafio na integração curricular, na escola de educação básica e na formação docente.

Hellen Cristina Sthal e Cátia Regina Assis Almeida Leal, com base no materialismo histórico-dialético, abordam as Concepções de homem, sociedade e 
mundo do trabalho em projetos de formação de cursos da área da saúde. As autoras partem do pressuposto que a finalidade do trabalho em saúde deve ser o cuidado com o ser humano, um cuidado holístico e multidimensional. Entretanto, observam os limites da formação dos profissionais da saúde na sociedade moderna, delineada pelo poder do capital e pelo fetichismo da mercadoria. $O$ modelo de saúde do SUS abre um cenário de mudança na perspectiva da atenção integral à saúde. Da mesma forma, as Diretrizes Curriculares Nacionais (DCN) para os cursos de graduação da área da saúde estabelecem o perfil de um profissional com formação generalista, humanista, crítica e reflexiva, capacitado para atuar nos diferentes níveis de atenção à saúde. Em contraposição, ao analisarem as concepções de homem e de sociedade que embasam os projetos de formação dos cursos de graduação da área da saúde da Universidade Federal de Goiás - UFG - Regional Jataí, as autoras observam que a concepção de homem predominante nos projetos de formação é a de um ser condicionado pelo meio físico-social, produtivo e adaptado à sociedade e ao mercado de trabalho.

Seguindo as análises sobre a perspectiva de uma formação integral e articulada ao trabalho, Egídio Martins e Valdiléia Carvalho da Silva apresentam o artigo $A$ práxis política como atividade formativa dos trabalhadores da pesca da Colônia Z-16 de Cametá-PA. Os autores partem da seguinte questão: qual a concepção de formação que se materializa no contexto das relações de produção-formação e práxis política dos pescadores da Colônia Z-16? Com base em autores do campo marxista (Marx, Engels, Thompson, Gramsci, Vasquez), abordam a práxis política dos pescadores, visto que no seu cotidiano organizamse para dar conta de sua subsistência e nessa articulação revelam elementos que se contrapõem ao poder instituído.

Celia Cristina Pereira da Silva Veiga e José dos Santos Souza abordam a Formação inicial de soldados da Polícia Militar do Estado do Rio de Janeiro no contexto da reforma gerencial do Estado. Visando explicitar as interfaces entre as ações e formulações no campo da política de segurança pública e a política pedagógica, os autores tomam como objeto de análise o Curso de Formação de Soldados (CFSd) da Polícia Militar do Estado do Rio de Janeiro (PMERJ). O artigo está organizado em três seções: a reforma do Estado e da propagação do ideário gerencialista; as interferências da reforma gerencial na política de 
segurança; e, por último, a forma como as mudanças na política de segurança pública decorrentes da reforma gerencial se materializam nas ações e nas formulações da PMERJ para a formação inicial de seus soldados. Após análises documentais e fontes empíricas, sustentadas por denso aporte teórico, os autores concluem que a política de segurança pública explicitada em documentos no estado do Rio de Janeiro não se materializa na política pedagógica do CFSd. Observam, ainda, a adoção de práticas inadequadas destinadas à manutenção e reprodução dos padrões tradicionalistas, uma pedagogia que forja profissionais submissos e minimamente reflexivos, e um currículo aplicado por meio de uma pedagogia da coerção, a partir de punições e excessiva prática de atividades físicas.

Maria da Conceição dos Santos Costa, no artigo Trabalho docente na educação básica: as condições e a jornada de trabalho na educação física na educação de jovens e adultos trabalhadores do estado do Pará, examina, mediante pesquisa com docentes da rede municipal de Belém do Pará, a configuração do trabalho do docente de Educação Física atuante na EJA. As condições precárias de trabalho e jornadas extenuantes são elementos importantes abordados pela autora. $O$ artigo compõe-se de três partes: na primeira apresenta brevemente a intrínseca relação entre trabalho e trabalho docente na sociedade capitalista, buscando situar neste debate a especificidade do docente da Educação Física que atua na EJA. Na segunda parte procura evidenciar, partindo de depoimentos dos próprios professores de Educação Física, as péssimas condições de trabalho como um forte impeditivo para o desenvolvimento do trabalho com os jovens e adultos trabalhadores na escola, que leve em conta uma dimensão mais ampla da Educação Física. Também revela, entre outros aspectos, o impacto que tal condição de trabalho apresenta na constituição da subjetividade docente. Por fim, reforça a existência de um intenso processo de degradação das condições de trabalho do docente de Educação Física que atua na EJA.

Ainda na esteira da discussão sobre a precarização das condições de trabalho, o artigo de Regis Arguelles da Costa, intitulado O Programa Mais Educação e a gestão do trabalho escolar: um estudo em Duque de Caxias/RJ, analisa o processo de implantação e gestão do Programa Mais Educação (PME) 
em uma unidade escolar de Duque de Caxias, município do Estado do Rio de Janeiro. O autor problematiza sobre a forma como se dá a incorporação pela gestão local das novas determinações advindas com o PME e seus desdobramentos na administração da escola pública e no cotidiano do trabalho escolar. Sua análise funda-se na compreensão de que o modelo gerencial, ao ser incorporado no setor público, impõe a presença de parcerias com o setor privado, a utilização do voluntariado, a focalização da pobreza e controle social. Tais medidas são a expressão do estágio de desenvolvimento do programa neoliberal da Terceira Via no Brasil. Dividido em duas partes, o artigo apresenta os objetivos do PME e as novas modalidades de gestão da escola pública ali presentes, bem como, mediante entrevistas com professores e equipe diretiva de escolas, procura evidenciar o processo de implementação do Programa, atentando para as suas fragilidades, inconsistências, mas também os elementos contraditórios vivenciados por seus entrevistados.

No artigo $A$ formação do licenciado nos Institutos Federais do Nordeste e $o$ ensino médio integrado à educação profissional, Olívia Morais de Medeiros Neta, Ulisséia Ávila Pereira e Nina Maria da Guia de Sousa Silva abordam as licenciaturas ofertadas nos Institutos Federais, na região Nordeste, e o Ensino Médio Integrado à Educação Profissional. As autoras objetivam apreender, nos cursos de licenciatura em Letras, Matemática, Química e Geografia dos Institutos Federais de Educação, Ciência e Tecnologia da região Nordeste, as concepções de formação docente voltadas à formação para a Educação Básica, particularmente o Ensino Médio Integrado (EMI). O estudo, de caráter documental e empírico, com aplicação de questionários a professores e estudantes concluintes dos cursos supracitados, revela que as concepções de formação docente e EMI constantes nos Planos de Desenvolvimento Institucional e nos Projetos Políticos Pedagógicos dos IFs estão associados aos princípios norteadores do currículo das licenciaturas de Letras, Matemática, Química e Geografia voltados à formação para a Educação Básica, tangenciando a formação de docentes para atuação no EMI.

Os autores Marcelo Lima, Renan dos Santos Sperandio, Samanta Lopes Maciel e Zilka Teixeira no artigo Integração curricular no IFES: limites e possibilidades da pesquisa-ação investigam, por meio de uma pesquisa-ação 
realizada no IFES, o fortalecimento da integração curricular do ensino médio à educação profissional técnica de nível médio na Rede Federal. Com uma duração de quatro anos (2013-2016), abrangendo diversos campi, envolvendo os cursos técnicos integrados em Agroindústria, Administração, Mecânica, Eletrotécnica e Edificações, os autores relatam de forma pormenorizada esta experiência de pesquisa e ao mesmo tempo de intervenção. Ressaltam seus limites e as possibilidades de pensar uma ação integradora, sobretudo no campo do diagnóstico e da formação docente, cujas consequências são ainda pouco visíveis no momento da pesquisa. No entanto, os autores apontam as tensões e contradições presentes neste processo, com destaque para aquilo que consideram como uma "resistência muda" quando estava em jogo a necessidade de uma mudança efetiva na prática docente.

Além dos artigos que compõem o número temático, a Revista conta com mais três artigos de demanda contínua. O primeiro deles, intitulado Intensificação e precarização social do trabalho de professores de escola pública: um estudo exploratório na região da Baixada Fluminense (RJ), foi escrito por Luiz Armando Arouca Morais, Katia Reis de Souza e Gideon Borges dos Santos. O objetivo do artigo foi analisar as relações entre o trabalho e a saúde de professores do ensino fundamental em escola pública. Por meio de entrevistas com professores, os autores observam o aprofundamento da intensificação e precarização social das condições do trabalho docente em escolas públicas, com implicações na saúde dos professores.

Abelardo Bento Araújo apresenta o artigo O produto do trabalho educativo na política de monitoramento da qualidade da educação: notas de economia política. Este desenvolve uma análise de cunho teórico, com base na economia política, sobre as especificidades do trabalho educativo tendo em vista 0 monitoramento da qualidade da educação por meio de escores de rendimento em testes em larga escala. Trata do trabalho humano em seu sentido geral, do trabalho humano sob a égide do capital e tece considerações sobre a noção de produto do trabalho educativo. Apresenta questões fundamentais sobre a adequação da política de monitoramento, tendo em conta a especificidade da atividade educativa e dos próprios fins da educação. 
$\mathrm{O}$ artigo de Wanderson Pereira Araújo aborda $A$ maquinaria e $\mathrm{O}$ aumento na produtividade pelo trabalho intelectual: observações a partir de Karl Marx. $O$ propósito de autor é analisar o trabalho intelectual na complexidade da atividade docente, inserido na formação profissional dos trabalhadores e na produção e aplicação da ciência e da tecnologia no campo da agricultura. A análise parte de observações de atividades docentes nos Institutos Federais (IFs) com o aporte de categorias desenvolvidas por Karl Marx na obra O Capital, no que diz respeito especialmente à teoria do valor e ao trabalho produtivo/improdutivo.

Em Teses e Dissertações, o presente número da revista TN traz o Resumo expandido da tese de doutorado de Vítor Bemvindo, intitulada Por uma história da educação politécnica: concepções, experiências e perspectivas. Nele, o autor apresenta as questões centrais de sua tese, organizadas em torno da análise histórica do conceito de educação politécnica, em permanente disputa por distintos grupos e classes sociais que deram ao termo diferentes sentidos políticos-pedagógicos, associados aos projetos de sociedade defendidos por cada um destes grupos. A partir de tais análises, Bemvindo destaca os casos da Escola Politécnica de Saúde Joaquim Venâncio (EPSJV) e do Instituto Politécnico da UFRJ em Cabo Frio (IPUFRJ), como experiências bem-sucedidas de ensino médio integrado referenciadas na politecnia

Na seção Memória e Documentos, o material em destaque é o Memorial apresentado pela professora Eunice Schilling Trein, no seu processo de progressão para professora titular da Faculdade de Educação da Universidade Federal Fluminense (UFF). Intitulado Um Tributo à Escola Pública, o memorial faz, ao mesmo tempo, um rigoroso e afetivo resgate da trajetória pessoal e coletiva de uma educadora que, nas variadas esferas dos espaços educativos ensino, pesquisa e extensão - procura reforçar "a construção integral do ser humano e a construção de uma sociedade emancipada", reconhecendo o espaço escolar como aquele em que se explicita a disputa de diferentes projetos societários, e como essa disputa se desdobra no mundo do trabalho, inclusive com consequências socioambientais - duas áreas às quais se dedicou e ainda se dedica a conhecer e atuar, na defesa de experiências de educação referenciadas socialmente e que se propõem públicas, democráticas e transformadoras. 
Para finalizar, lembramos que em 2018 comemoram-se os 200 anos de nascimento de Karl Marx, um dos mais importantes pensadores de nossa história. Sua obra constitui a essência fundamental não apenas para compreender o modo de produção capitalista, mas a sua superação. Dedicou toda a sua vida na construção de uma teoria social com forte impacto nos movimentos revolucionários das gerações do passado até os dias atuais. Comemorar esta data é manter vivo o seu pensamento, não no plano da nostalgia, mas no plano da práxis. Neste sentido, encerramos esta apresentação com a compreensão de que os artigos ora apresentados perfilam-se a seu modo, mesmo que por diferentes entradas e níveis de aprofundamentos, dentro do que consideramos uma tentativa de entender a realidade à luz de uma teoria crítica, que sinalize para a compreensão e transformação da realidade, posição esta tão cara ao nosso GT!

Publicado em: 13 de junho de 2018 